\title{
Renal agenesis in mice homozygous for a gene trap mutation in the gene encoding heparan sulfate 2-sulfotransferase
}

\author{
Simon L. Bullock, ${ }^{1}$ Judy M. Fletcher, ${ }^{2}$ Rosa S.P. Beddington, ${ }^{1,4}$ and Valerie A. Wilson ${ }^{1,3}$ \\ ${ }^{1}$ Laboratory of Mammalian Development, Medical Research Council (MRC) N ational Institute for Medical Research, \\ The Ridgeway, London NW7 IAA, UK; ${ }^{2}$ MRC Human Genetics Unit, Western General Hospital, Edinburgh EH4 2XU, UK; \\ ${ }^{3} \mathrm{M}$ olecular M edicine Centre, Western General Hospital, Edinburgh EH4 2XU, UK
}

\begin{abstract}
Heparan sulfate proteoglycans have been implicated in the presentation of a number of secreted signaling molecules to their signal-transducing receptors. We have characterized a gene trap mutation in the gene encoding a heparan sulfate biosynthetic enzyme, heparan sulfate 2-sulfotransferase (HS2ST). Transgenic mice were generated from embryonic stem cells harboring this insertion. lacZ reporter gene activity in heterozygous embryos demonstrates that the gene is expressed differentially during embryogenesis, presumably directing dynamic changes in heparan sulfate structure. Moreover, mice homozygous for the H s2st gene trap allele die in the neonatal period, exhibiting bilateral renal agenesis and defects of the eye and the skeleton. Analysis of kidney development in H s2st mutants reveals that the gene is not required for two early events-ureteric bud outgrowth from the Wolffian duct and initial induction of Pax-2 expression in the metanephric mesenchyme. It is required, however, for mesenchymal condensation around the ureteric bud and initiation of branching morphogenesis. Because 2-0-sulfation has been shown to influence the functional interactions of ligands with heparan sulfate in vitro, we discuss the possibility that the H s2st mutant phenotype is a consequence of compromised interactions between growth factors and their signal-transducing receptors. These data provide the first genetic evidence that the regulated synthesis of differentially glycosylated proteoglycans can affect morphogenesis during vertebrate development.
\end{abstract}

[Key Words: Gene trap; heparan sulfate proteoglycan; sulfotransferase; kidney; induction]

Received N ovember 18, 1997; revised version accepted A pril 7, 1998.

Heparan sulfate proteoglycans (HSPGs) are expressed at the surface of most animal cells, where they interact with a variety of proteins, including extracellular matrix components, growth factors, degradative enzymes, and protease inhibitors (for review, see Bernfield et al. 1992). Heparin-like molecules have been implicated in the presentation of a number of secreted signaling molecules, such as members of the fibroblast growth factor (FGF), Wingless/Wnt, transforming growth factor- $\beta$ (TGF- $\beta$ ) and Hedgehog families (Rapraeger et al. 1991; Yayon et al. 1991; Lee et al. 1994; Reichsman et al. 1996; Ruppert et al. 1996; Binari et al. 1997), to their signal-transducing receptors. In some cell types, there is an obligate requirement for cell-surface HSPGs in the FGF-signaling pathway leading to the proposal that these molecules function as low-affinity receptors facilitating the interaction of ligands with high-affinity receptor tyrosine kinases (Klagsbrun and Baird 1991; Yayon et al. 1991; Schlessinger et al. 1995). In addition, HSPGs may bind growth factors in the extracellular matrix, altering their stabil-

${ }^{4}$ Corresponding author.

E-MAIL rbeddin@ns1.nimr.mrc.ac.uk; FAX 00441819138543. ity and modulating their effective concentration (Saksela and Rifkin 1990; Reichsman et al 1996).

The specificity of HSPG-ligand interactions resides, at least in part, in the structure of the heparan sulfate glycosaminoglycan side chains, which vary in number, length, sequence composition, and sulfation pattern between cell type and developmental stage (Gallagher et al. 1986; N urcombe et al. 1993; Kato et al. 1994). Therefore, the regulated synthesis of differentially gl ycosylated proteoglycans may represent an additional means to regulate cell-cell communication during development.

In a gene trap screen desi gned to identify genes important in mouse embryogenesis, we recovered an integration into the gene encoding heparan sulfate 2-sulfotransferase (HS2ST). This enzyme catalyzes the transfer of sulfate to position 2 of the iduronic acid component of heparan sulfate (Kobayashi et al. 1997). We show that Hs2st is expressed differentially during embryogenesis, presumably reflecting changes in the proteoglycan side chain structure. Moreover, mice homozygous for the gene trap mutation exhibit bilateral renal agenesis, resulting from a failure of ureteric bud branching and mesenchymal condensation, and defects of the eye and skeleton. These data provide the first genetic demonstration 
of heparan sulfate function in vertebrate embryonic development.

\section{Results}

ST 125 represented one embryonic stem (ES) cell line selected from a gene trap screen designed to identify integrations into genes encoding secreted or transmembrane proteins expressed during early organogenesis (Skarnes et al . 1995; see M aterials and M ethods). Expression of the lacZ reporter was demonstrated in mid-gestation chimeras (data not shown) and subsequently adult chimeras were generated to transmit the integration through the germ line and establish a line of mice heterozygous for the gene trap all el e (designated Hs2st ${ }^{T g N S t 125 N \text { imr }}$ ). These heterozygotes were viable and fertile, displ aying no overt defects by 18 months of age.

\section{Characterization of ST 125 insertion site}

5' RACE was used to clone a portion of the trapped gene from the ST 125 cell line, which proved to be the previously unidentified mouse homolog of hamster Hs2st. The protein product of this gene catalyzes the transfer of sulfate from $3^{\prime}$-phosphoadenosine $5^{\prime}$-phosphosulfate to position 2 of L-iduronic acid in heparan sulfate. The gene has been cloned recently from Chinese hamster ovary (CHO) cells (Kobayashi et al. 1997) and the protein was predicted to be localized to the Golgi in a type II membrane orientation.

A probe corresponding to the ST 125 5' RACE product was used to isolate a 2.1-kb mouse Hs2st clone from a 8.5-day postcoitum (d.p.c.) mouse embryo cDN A library. In addition, the same probe was used to isolate a Xenopus homolog of Hs2st from a gastrula-stage cDNA library using low-stringency screening. Sequence anal ysis demonstrated that the protein product of $\mathrm{Hs} 2 \mathrm{st}$ is highly conserved in vertebrates, sharing $99 \%$ and $90 \%$ amino acid sequence identity with its hamster and Xenopus homologs, respectively (Fig. 1A). Furthermore, the mouse protein shares $58 \%$ amino acid sequence identity over a 245-amino-acid region with the predicted protein product of the Drosophila melanogaster S1 CDNA. The function of the $\mathrm{Sl}$ gene is unknown but it was identified as a candidate gene for the Sd mutation associated with the Segregation distorter mei otic drive system (Powers and Ganetzky 1991). Interestingly, one highly conserved block of sequence present in vertebrate HS2STs displayed significant homology with a large number of enzymes that catalyze the transfer of sulfate to a variety of molecules (Fig. 1B). This suggests that this region may be important for the catalytic mechanism al though it is absent from some sul fotransferases, incl uding heparan sulfate N-deacetylase/ N-sulfotransferase (Hashimoto et al . 1992). It would, however, be present in the fusion protein generated by the gene trap insertion (Fig. 1A).

ST 125 comprises a single gene trap insertion that disrupts the Hs2st transcript

FISH analysis to G-banded metaphase spreads of ST 125
ES cells (Fig. 1C) revealed that Hs2st maps to a subtelomeric location on chromosome $3(3 \mathrm{H})$. Furthermore, only a singl e gene trap vector insertion site was evident, localized to chromosome 3, and it coincided precisely with the position of Hs2st (Fig. 1C). Molecular characterization of the mutant allele revealed a single copy of the gene trap vector and restriction mapping of genomic DNA and PCR-amplified flanking regions revealed no microdel etions or rearrangements within $10 \mathrm{~kb}$ on either side of the insertion site (data not shown). FISH analysis was also used to show that a genomic human HS2ST sequence hybridized to human chromosome 1p31 (Fig. 1D), a region showing synteny with mouse chromosome 3H (DeBry and Seldin 1996). The human HS2ST map position was refined further by radiation hybrid mapping to 3.87cR from D1S2167 on chromosome 1.

The junction in the 5' RACE product of the endogenous mouse sequence and the gene trap vector splice acceptor sequence predicted that amino acid residues carboxy-terminal to position 196, including several re gions with a high degree of evolutionary conservation, would not be encoded by the gene trap allele (Figs. 1A and 2A). Given the recessive nature of the Hs2st mutant phenotype (see bel ow) the gene trap insertion is likely to cause a loss-of-function mutation; however, we cannot state categorically that it is a null allele.

Northern hybridization was performed on RNA isolated from wild-type, heterozygous, and homozygous embryos generated by intercrossing heterozygotes. Embryos were genotyped using a PCR-based assay that distinguished between the wild-type and the gene trap allele (see M aterials and M ethods). This analysis reveal ed that Hs2st transcripts were disrupted by the gene trap integration (Fig. 2B). Using a probe specific to the $5^{\prime}$ RACE product, a transcript of $2.4 \mathrm{~kb}$ was detected in RN A derived from wild-type, but not from homozygous, mutant embryos. In the latter, only a $5.6-\mathrm{kb}$ band (the size predicted for the gene trap fusion mRNA) was observed and no wild-type transcript could be detected. Heterozygotes were found to possess the wild-type and fusion transcripts in equal amounts. Low levels of a 4-kb transcript, possibly representing an al ternative splice product, were present in wild-type RN A but were undetectable in homozygous mutant RNA, indicating that this transcript was also disrupted by the transgene insertion.

\section{Embryonic expression pattern of Hs2st}

The lacZ expression pattern in heterozygous embryos was examined at various developmental stages (Fig. 3). At 7.5 d.p.c., all three germ layers expressed lacZ, although there appeared to be elevated expression in the embryonic ectoderm and the node (Fig. 3A). Widespread expression persisted at 8.5 d.p.c., although $\beta$-gal activity was clearly stronger in rhombomeres 2 and 4 and branchial arches 1 and 2 (which are populated by neural crest from these rhombomeres) (Fig. 3B,C). At 10.5 d.p.C., the dorsal and ventral aspects of the neural tube, brain, and midbrain-hindbrain junction showed the most intense staining (Fig. 3D,E). A day later in development, el evated 

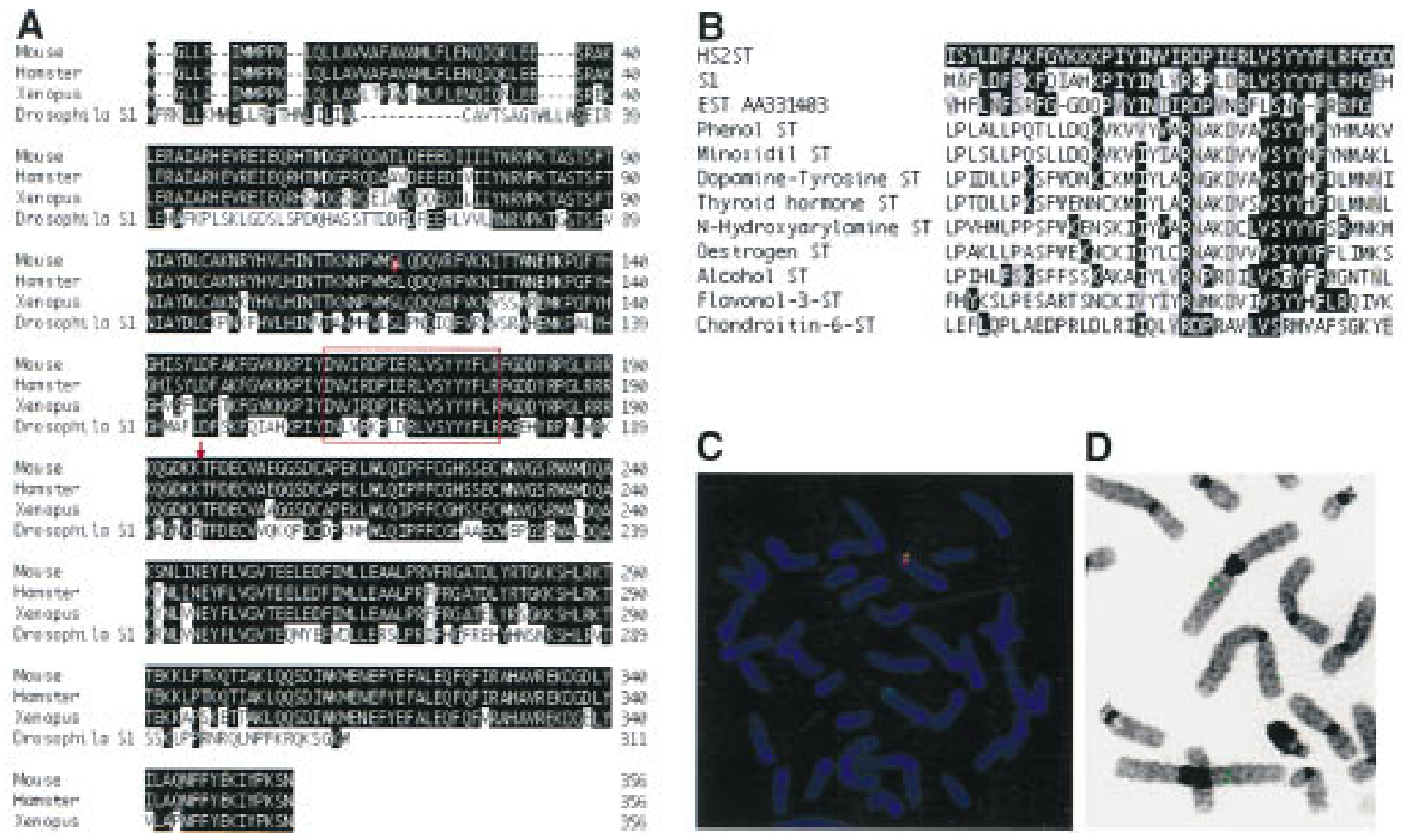

Figure 1. Characterization of the ST 125 insertion site. (A) Alignment of deduced amino acid sequence of mouse Hs2st CDNA with those of hamster and Xenopus Hs2st and Drosophila S1 cDN As. Identical residues are boxed in black. The published carboxy-terminal 52 amino acids of Drosophila S1 are excluded on the basis of new sequence data (C. M errill and B. Ganetzky, pers. comm.). (Arrow) Position of gene trap vector insertion site. Residues carboxy-terminal to this site are not predicted to be encoded by the gene trap allele. The conserved block sharing homology with several sulfotransferases is boxed in red. (B) Partial alignment of hamster HS2ST (GenBank protein accession no. 2196446) with human phenol sulfotransferase (accession no. 1711607), rat minoxidil sulfotransferase (accession no. 310179), rat dopamine-tyrosine sulfotransferase (accession no. 1711584), human thyroid hormone sulfotransferase (accession no. 2290540), rat N-hydroxyarylamine sulfotransferase (accession no. 1711569), rat estrogen sulfotransferase (accession no. 1711599), mouse alcohol sulfotransferase (accession no. 1711587), Flaveria bidentis flavonol-3-sulfotransferase (accession no. 1706738), chick chondroitin-6-sulfotranferase (accession no. 2494838), Drosophila S1 (accession no. 11013), and the predicted protein product of a human EST (GenBank nucleotide accession no. AA 334103). Identical residues are shaded in black, conservative changes are shaded in gray. (C) M etaphase spread of ST 125 ES cells subjected to fluorescent in situ hybridization with a probe specific to the mouse Hs2st genomic sequence (green) and a probe specific to the gene trap vector (red). A reas of overlap between the two signals are yellow. Chromosomes were counterstained with DAPI (blue). Hybridizing chromosomes were classified as chromosome 3, using Quips Karyotyper (data not shown). In 15 spreads, no other chromosome consistently gave a signal. (D) FISH to metaphase spread from human blood, using a human HS2ST genomic fragment as a probe. Both copies of chromosome 1p3 show hybridization (green spots). In 10 spreads no other chromosome consistently gave a signal.

$\beta$-gal activity was found in the floor plate (Fig. 3F,G) and the sclerotome (data not shown). At 12.5 d.p.c., both the floor plate (data not shown) and the roofplate exhibited strong lacZ staining as did the mesenchyme of the limb and of the developing whisker follicles (Fig. 3H). At 13.5 d.p.c., lacZ expression predominated in embryonic mesenchyme, especially at sites of epithelial-mesenchymal interactions such as the developing teeth (data not shown) and whisker follicles (Fig. 3l). Strong staining was also apparent in the perichondria of the cartilaginous skel eton (Fig. 3J), an important site for the regulation of skeletal differentiation (Vortkamp et al. 1996). $\beta$-gal activity in $\mathrm{Hs} 2 \mathrm{st}^{+1}-$ embryos faithfully reflected the endogenous gene expression pattern as reveal ed by in situ hybridization using an antisense Hs2st probe (Fig. 3B,D,F; data not shown).
Hs2st is required for metanephric development

Genotype analysis of prenatal litters between 8.5 and 15.5 d.p.c. indicated that there was no significant death of homozygotes before the latter stages of gestation [73 homozygotes $(27 \%)$ identified out of a total of $273 \mathrm{em}$ bryos]. Homozygous mutants, however, were either stillborn or died within $24 \mathrm{hr}$ of birth and showed bilateral renal agenesis. This completely penetrant phenotype (Table 1; Fig. 4) was probably responsible for the neonatal lethality. No abnormalities were observed in other parts of the urogenital system (Fig. 4) or in other internal organs. All heterozygotes and wild types examined had overtly normal kidneys.

In amni otes, the permanent (or metanephric) kidney is formed by the interaction of two mesodermal deriva- 


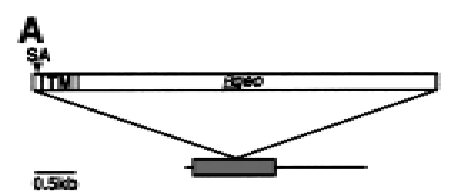

B

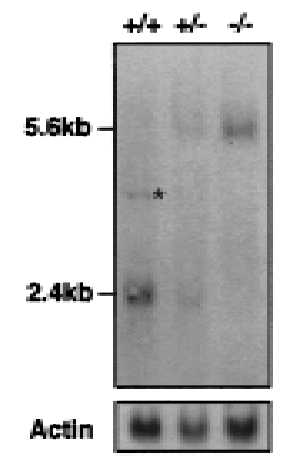

Figure 2. Hs2st transcripts are disrupted by the gene trap insertion. (A) Schematic of mouse Hs2st CDN A showing position of gene trap vector insertion site. The shaded box represents a 1068-bp ORF; the integration site corresponds to position 588 (start of translation =position 1). (SA) Splice acceptor; (TM) transmembrane-encoding region. (B) $\mathrm{N}$ orthern hybridization of $10 \mu \mathrm{g}$ of total RNA isolated from a wild-type $(+/+)$, a heterozygote $(t-)$, and a homozygous mutant $(-t \rightarrow$ 15.5-d.p.c. embryo using a probe specific to the ST 125 5' RACE product. The weak 4-kb signal (asterisk) detected in the wild-type RN A may represent an endogenous unprocessed Hs2st RN A or splice variant that is disrupted in the mutants and is represented too poorly in a heterozygote RNA population to be visualized. $\beta$-Actin was used as a loading control.

tives, the epithelial ureteric bud and the metanephric mesenchyme. At 10.75 d.p.c. in the mouse, the ureteric bud emerges from the Wolffian (or nephric) duct, thereby contacting the adjacent metanephric mesenchyme. The metanephric mesenchyme induces the ureteric bud to elongate and branch repeatedly, ultimately forming the collecting duct system and, at the same time, the ure teric bud tips prevent the metanephric mesenchyme from undergoing apoptosis and induce it to condense, epithelialize, and differentiate into secretory nephrons (Grobstein 1953; for review, see Bard et al. 1996; Vainio and M üller 1997).

To investigate the embryological basis of the renal defect, the developing kidneys of $\mathrm{Hs}_{2} \mathrm{st}^{-1}$ - mutants were compared with those of normal littermates. At 11.5 d.p.c., all wild-type and heterozygous kidney rudiments examined $(n=85$, where $n=$ number of kidneys examined) contained a ureteric bud that had bifurcated once or, less frequently, twice, and was surrounded by a mantle of mesenchymal condensation (Fig. 4C,E). In contrast, $\mathrm{Hs} 2 \mathrm{st}^{-1-}$ kidney rudiments $(n=48)$ contained an unbranched ureteric bud that was not surrounded by condensed metanephric mesenchyme (Fig. 4D,F). In homozygous mutants at 12.5 d.p.c., no branching of the ureteric bud had occurred and there were no overt signs of mesenchymal condensation (data not shown; $n=44$ ), demonstrating that renal development was arrested rather than delayed. Therefore, Hs2st is not required for the initial outgrowth of the ureteric bud from the Wolffian duct but rather for ureteric bud branching and mesenchymal condensation. The presence of relatively long unbranched ureters in neonatal Hs2 $\mathrm{st}^{-1-}$ mutants (Fig. $4 \mathrm{~B}$ ) shows that the gene is not requi red for the directional growth of this tissue.

\section{Expression of Hs2st during kidney development}

In heterozygotes at 10.75 d.p.c., weak $\beta$-gal activity was evident in the metanephric mesenchyme, Wolffian duct, and emergent ureteric bud (Fig. 5A). At 11.5 d.p.c., re-

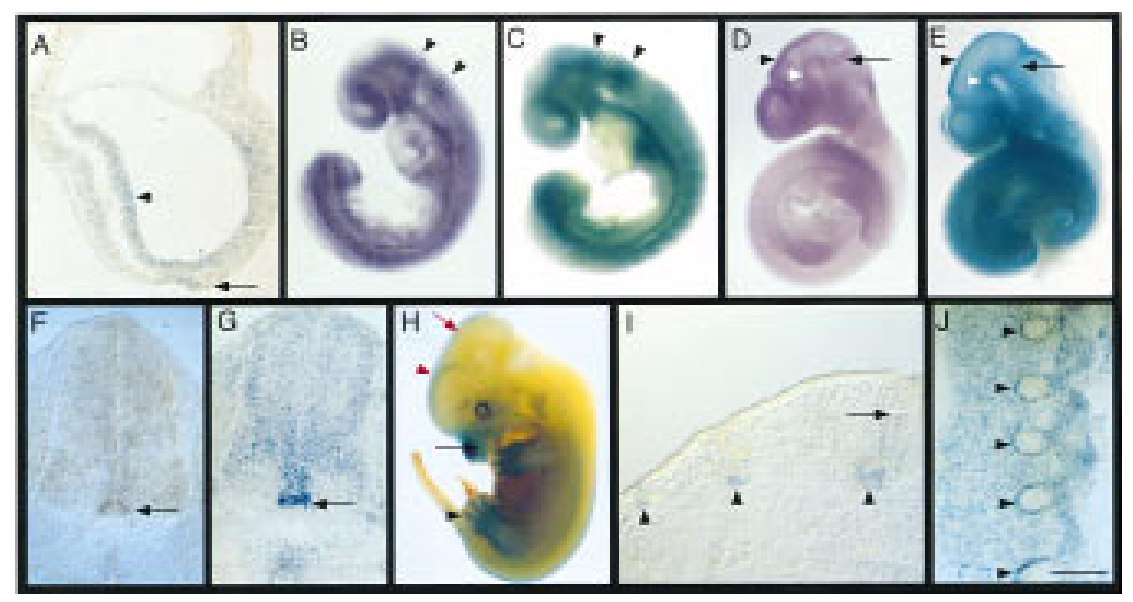

Figure 3. Expression pattern of Hs2st revealed by lac $Z$ reporter activity in heterozygous embryos (A, C,E, G, H, I , J) and wholemount in situ hybridization with an antisense Hs2st probe (B,D,F). (A) A 7.5-d.p.c. sagittal section of a late headfold stage embryo (anterior to the left) showing widespread $\beta$-gal activity, with el evated levels in the node (arrow) and embryonic ectoderm (arrowhead). (B,C) An 8.5 d.p.c., lateral view of 12 somite embryos. Widespread expression persists, but there is elevated $\beta$-gal activity in rhombomeres 2 and 4 (arrowheads). (D,E) Lateral view of a 10.0d.p.c. embryo showing el evated expression in the roof plate (black arrowhead), floor plate (white arrowhead), and midbrainhindbrain junction (arrow). ( $F, G)$ Transverse section through an 11.5-d.p.c. embryo. Strong expression is exhibited by the floor plate (arrow). (H) A 12.5-d.p.c. Iateral view. The roof plate (red arrow), tel encephalic vesicles (red arrowhead), vibrissa follicles (black arrow), and limb mesenchyme (black arrowhead) express high levels of lacZ. (I) Transverse section through a 13.5-d.p.c. embryo showing vibrissa follicle expression localized to the mesenchyme (arrowheads) and the developing hairshaft (arrow). (J) Sagittal section through a 14.5-d.p.c. embryo, dorsal to the left. Reporter gene activity is associated with the perichondria surrounding the ribs (arrowheads). Scale bar in J: $125 \mu \mathrm{m}(\mathrm{A}) ; 425 \mu \mathrm{m}(\mathrm{B}, \mathrm{C})$; $1000 \mu \mathrm{m}(\mathrm{D}, \mathrm{E}) ; 150 \mu \mathrm{m}(\mathrm{F}, \mathrm{G}) ; 1800 \mu \mathrm{m}(\mathrm{H}) ; 500 \mu \mathrm{m}(\mathrm{I}) ; 375 \mu \mathrm{m}(\mathrm{J})$. 
Table 1. Defects observed in neonatal Hs2st mutants

\begin{tabular}{|c|c|c|c|c|}
\hline \multirow[b]{2}{*}{ Phenotype } & \multirow{2}{*}{$\begin{array}{l}\text { Bilateral } \\
\text { renal } \\
\text { agenesis }\end{array}$} & \multirow[b]{2}{*}{$\begin{array}{l}\text { Cleft } \\
\text { palate }\end{array}$} & \multicolumn{2}{|c|}{ Extra postaxial digit ${ }^{a}$} \\
\hline & & & $\begin{array}{l}\text { of one } \\
\text { forelimb }\end{array}$ & $\begin{array}{l}\text { of both } \\
\text { forelimbs }\end{array}$ \\
\hline $\begin{array}{l}\text { No. with defect/ } \\
\text { no. examined }\end{array}$ & $29 / 29$ & $12 / 29$ & $16 * / 29$ & $5 / 29$ \\
\hline
\end{tabular}

${ }^{a}(*)$ Of which, 13 had an extra digit on the right forelimb.

porter gene expression was almost undetectable in the ureteric bud epithelium; in contrast, the metanephric mesenchyme expressed high levels of lacZ (Fig. 5B). To follow Hs2st expression during subsequent metanephric development, 11.5-d.p.c. Hs2st ${ }^{+/}$- kidney rudiments were cultured in vitro (Fig. 5C,D). After $24 \mathrm{hr}$ of culture, I acZ was no longer expressed in the ureteric bud. Strong $\beta$-gal activity, however, was apparent throughout the metanephric mesenchyme with the exception of maturing mesenchymal aggregates around the ureteric bud tips. Therefore, it would appear that Hs2st expression is rapidly down-regulated as the mesenchyme starts to differentiate. In 96-hr cultures, $\beta$-gal activity persisted in undifferentiated mesenchyme but was not evident in any of the maturing components of the kidney. This mirrored the situation in vivo; lacZ-expressing cells were localized to the mesenchyme at the periphery of the 14.5 d.p.c. Hs2st ${ }^{+1}$ kidney, where new nephric tubules were being induced (Fig. 5E). These data do not distinguish whether the primary defect in kidney development in homozygous mutants resides in the metanephric mesenchyme itself or stems from a very early defect in the nascent ureteric bud.

Expression of molecular markers for metanephric development in Hs2st mutants

Whole-mount in situ hybridization and immunohistochemistry was used to assay the expression of well-characterized markers of metanephric development in mutant embryos (Fig. 6). For each marker at each stage, a minimum of five and, in most cases, more than 12 mutant kidneys where compared with a similar number of heterozygous and wild-type littermates. The transcription factor Pax-2, as well as being expressed in the Wolffian duct, mesonephric tubules, and the ureteric bud epithelium, is induced in the metanephric mesenchyme following interaction with the ureteric bud (Dressler et al. 1990). In Hs2st $\mathrm{st}^{-1}$ urogenital systems at 11.5 and 12.5 d.p.c., Pax-2 expression in the Wolffian duct and the mesonephric tubules was identical to that seen in the normal situation. In the kidneys, however, only an unbranched Pax-2-expressing ureteric bud was present. At 12.5 d.p.c., wild-type and heterozygous kidneys contained a number of Pax-2-expressing mesenchymal aggregates surrounding branching ureteric bud tips (Fig. 6C). In contrast, in homozygous mutant mesenchyme there was only a relatively small patch of Pax-2expressing cells, which were located at some distance from the ureteric bud tip. It has been observed in vitro that, once induced, metanephric mesenchymal cells move away from the inducing tissue, thereby facilitating the induction of further mesenchyme (Saxén and Karkiinen-Jääskeläïnen 1975). Because mutants one day earlier in development (11.5 d.p.c.) did have Pax-2-expressing mesenchymal cells adjacent to the unbranched ureteric bud (Fig. 6B), it is likely that the paucity of cells expressing this protein at 12.5 d.p.c., and their remoteness from the ureteric bud, reflects an early transient signal between the ureteric bud and metanephric mesenchyme.

The Ret receptor tyrosine kinase and its ligand glial cell line-derived neurotrophic factor (GDN F) are components of a signaling pathway required for ureteric bud outgrowth from the Wolffian duct and collecting duct morphogenesis (Schuchardt et al. 1994, 1996; Durbec et al. 1996; M oore et al. 1996; Pichel et al. 1996; Sánchez et

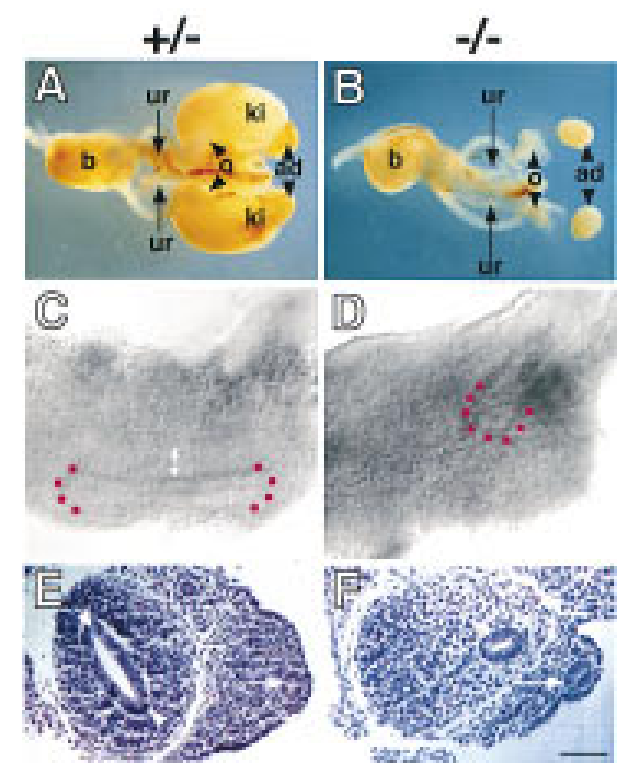

Figure 4. Bilateral renal agenesis in Hs2st mutant mice and its embryological basis. Dissected urogenital systems of normal (heterozygous) (A) and homozygous mutant (B) newborn mice. Homozygotes display bilateral renal agenesis and possess a blind-ended ureter (ur). The remainder of the mutant urogenital system is normal. (ad) Adrenal gland; (b) bladder; (ki) kidney; (o) ovary. (C-F) M orphology of representative 11.5-d.p.c. heterozygous $(C, E)$ and mutant $(D, F)$ embryonic kidney rudiments viewed in whole-mount (lateral view) $(C, D)$ or as $8 \mu \mathrm{m}$-transverse sections stained with haematoxylin and eosin $(E, F)$. (C) In heterozygotes, the ureteric bud has invaded the mesenchyme and bifurcated once to form a T-shape surrounded by a mantle of condensed mesenchyme (double-headed arrow). (D) In mutants, the ureteric bud has emerged from the Wolffian duct and invaded the mesenchymal blastema but failed to bifurcate and there are no overt signs of mesenchymal condensation. In $\mathrm{C}$ and $\mathrm{D}$ the position of the ureteric bud tip(s) is highlighted by red dots. (E) A dilated ureteric bud (arrowheads) is present in the heterozygotes surrounded by condensed mesenchyme. (F) In mutants, the ureteric bud (arrowhead) has not dilated, and there are no overt signs of condensation in the mesenchyme. (Arrow in $E$ and F) Wolffian duct. Scale bar in F, $1300 \mu \mathrm{m}$ (A and B); 30 $\mu \mathrm{m}(\mathrm{C}-\mathrm{F})$. 
Role of H s2st in kidney development

al. 1996; Trupp et al. 1996). In homozygotes, as in wildtype and heterozygous embryos, Gdnf transcripts were present in the uninduced metanephric mesenchyme at 10.75 d.p.c. (data not shown). Later, Gdnf is normally highly expressed in mesenchymal cells surrounding the ureteric bud tips (Fig. 6D,F; Durbec et al. 1996). In $\mathrm{Hs} 2 \mathrm{st}^{-1-}$ kidneys, Gdnf expression was attenuated at 11.5 d.p.c. (Fig. $6 \mathrm{E}$ ) and undetectable by 12.5 d.p.c. (Fig. 6F). In homozygous, heterozygous, and wild-type embryos, c-ret was expressed along the length of the Wolffian duct and in the emergent ureteric bud at 10.75 d.p.c. (data not shown). As the ureteric bud elongated and branched in heterozygous and wild-type embryos, c-ret expression resolved to the tips of branching ureteric buds (Fig. 6G). In Hs2st ${ }^{-1-}$ embryos the unbranched ureteric bud tips at 11.5 d.p.c. showed only low levels of c-ret expression (Fig. $6 \mathrm{H}$ ) and this expression had disappeared $24 \mathrm{hr}$ later (Fig. 6l). Therefore, following invasion of the metanephric mesenchyme by the ureteric bud, Hs2st appears to be required for maintenance of Gdnf expression and the localization of c-ret expression to the ureteric bud tip. Likewise, expression of Wnt11 in ureteric bud tips, which is compromized in vitro by inhibitors of glycosaminoglycan synthesis (Kispert et al. 1996), was not detected within the ureteric bud tip in Hs2st mutants foll owing invasion of the metanephric mesenchyme (Fig. 6K). The maintenance of apparently normal levels of expression within the ureter of markers such as Sox9 (Fig. 6L; Kent et al. 1996) and Pax-2 (see above) in mutants indicates that $\mathrm{Hs} 2 \mathrm{st}$ is not required for ureter identity but for maintenance of expression of genes associated specifically with branching ureteric bud tips.

\section{Skel etal and eye defects in Hs2st mutants}

As well as the kidney phenotype, other defects were apparent in homozygous mutants (Table 1; Fig. 7). There was a gl obal increase in bone mineral ization in homozygotes (Fig. 7B,C) and ectopic ossification of the sternum (six of seven mutants examined; Fig. 7E) and fusions of the cervical vertebrae (two of seven mutants examined; data not shown) occurred. In addition, a high frequency of mutants exhi bited post-axial polydactyly and interestingly this predominated in the right forelimb. A cleft of the secondary palate was also a frequent occurrence (Table 1). Bilateral col oboma of the iris, resulting from a perturbation of pigmented retinal epithel ium differentiation, was seen in 14/ 14 homozygotes examined (Fig. 7E). Histological sections revealed that mutants showed signs of retardation in eye development (data not shown). Furthermore, six of eight mutant animals had cataracts (data not shown). The expression pattern of Hs2st is consistent with a role in the development of the skeleton and the eye. The gene is highly expressed in the perichondria during skel etogenesis (Fig. 3J) and at the junction of the neural and pigmented retinal epithelia during development of the eye (data not shown). N o gross anatomical defects were evident in the brain and spinal cord, although a more detailed analysis may reveal subtle defects.

\section{Discussion}

Attribution of the mutant phenotype to the gene trap insertion in $\mathrm{Hs} 2 \mathrm{st}$

We have characterized a gene trap mutation in the geneencoding heparan sulfate 2-sulfotransferase. We find that mice homozygous for this mutation die in the neonatal period and invariably exhi bit bilateral renal agenesis and defects of the eye and skel eton. Cleft pal ate and polydactyly al so occur with incomplete penetrance.

The consistent segregation of the mutant phenotype with homozygosity for the unique gene trap insertion in Hs2st strongly suggests that it is disruption of this gene that is responsible for the lesions observed. Moreover, Hs2st is expressed in all tissues showing overt abnormalities and no intact Hs2st transcripts are de-

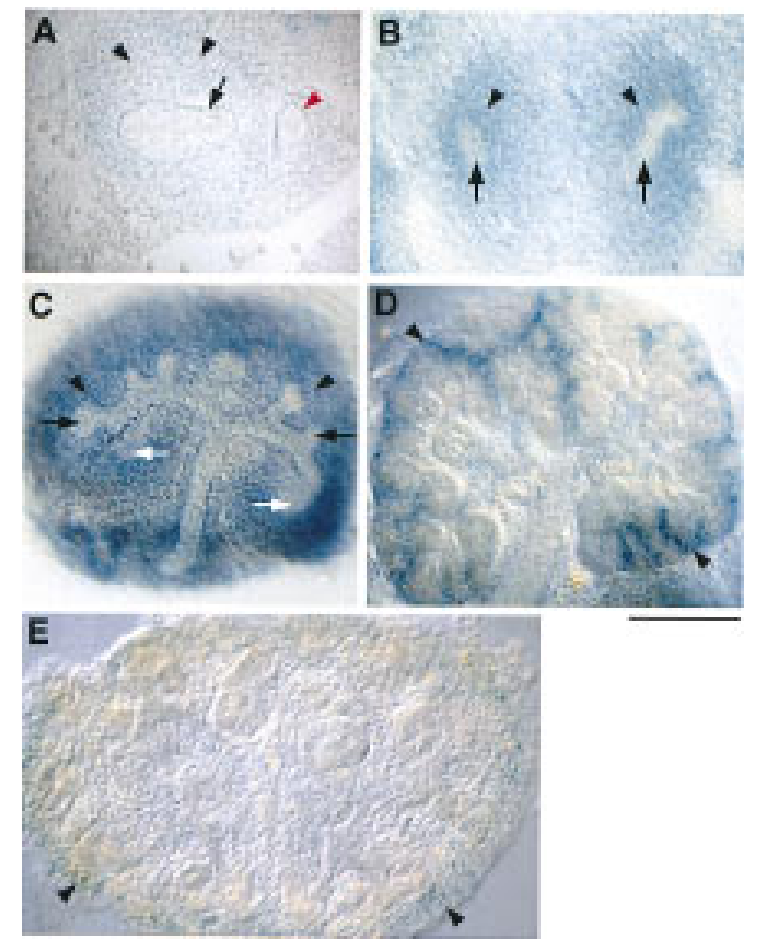

Figure 5. Hs2st expression during kidney development revealed by lac $Z$ reporter activity in heterozygous tissue. (A) Transverse section through a 10.75-d.p.c. embryo. Weak $\beta$-gal activity is detected in the metanephric mesenchyme (black arrowheads), ureteric bud epithelium (arrow), and the Wolffian duct (red arrowhead). (B) Transverse section through an 11.5d.p.c. embryo showing $\beta$-gal activity in the kidneys specific to the metanephric mesenchyme (arrowheads). Expression is absent from the ureteric bud (arrows). Kidney rudiments (11.5 d.p.c.) were cultured for $24 \mathrm{hr}$ (C) or $96 \mathrm{hr}$ (D) before X-gal staining. (C) Expression is restricted to the undifferentiated metanephric mesenchyme (black arrowheads) and is absent from the ureteric bud system (black arrows), and mesenchymal aggregates (white arrows). (D) Expression is localized to undifferentiated mesenchyme at the peri phery of the culture (arrowheads). (E) Section through a 14.5-d.p.c. embryo showing weak $\beta$-gal activity in mesenchyme at the periphery of the kidney (arrowheads) where new nephric tubules are being induced. Scale bar, $100 \mu \mathrm{m}(\mathrm{A}-\mathrm{C}) ; 200 \mu \mathrm{m}(\mathrm{D}, \mathrm{E})$. 
Figure 6. Expression of molecular markers for metanephric development in Hs2st mutants in dissected 11.5-d.p.c. kidney rudiments (A,B, $D, E, G, H)$ and 12.5-d.p.c. urogenital regions $(C, F, I, L)$. Heterozygous $(t-)$ or wild-type $(t+)$ $(A, D, G, J$ and left-hand specimen in $C, F, I, L)$ and homozygous mutant $(-\rightarrow-(B, E, H, K$ and righthand specimen in $C, F, I, L)$ specimens subjected to immunostaining with anti-Pax-2 antibody (A-C) or whole-mount in situ hybridization with probes specific to Gdnf (D-F), C-ret (G-I), Wnt11 (I,K), or Sox9 (L). Kidney rudiments are label ed with black arrowheads in C, F, I, and L. (A) At 11.5 d.p.C, Pax-2-positive cells are abundant in the metanephric mesenchyme surrounding the ureteric bud, which also expresses Pax-2 and has bifurcated twice. (B) In mutants at 11.5 d.p.c., Pax-2 expression is detected in the unbranched ureter (black arrow) and in the mesenchyme concentrated in a small population of cells at a distance from the ureteric bud tip. N ote the "stream" of Pax-2-positive cells adjacent to the bud tip (white arrow). (C) At 12.5 d.p.c., Pax-2 expression is localized to the mesonephric tubules (mt), Wolffian ducts (wd), and ureteric epithelium in mutant and heterozygous or wild-type urogenital systems. Mutants have unbranched Pax-2-expressing ureters (white arrowheads) and possess few Pax-2 positive cells in the mesenchyme (black arrowheads). (D) At 11.5 d.p.c., strong Gdnf expression is detected in the mesenchyme surrounding the bifurcated ureteric bud. (E) In mutants, Gdnf expression in mesenchyme adjacent to the unbranched ureteric bud is attenuated (black arrow).
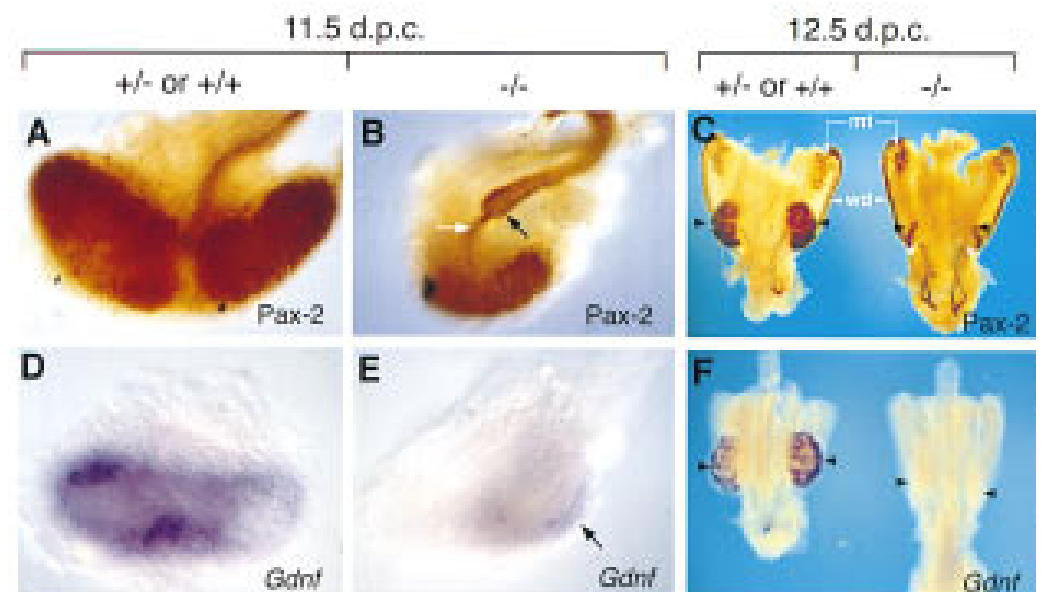

E
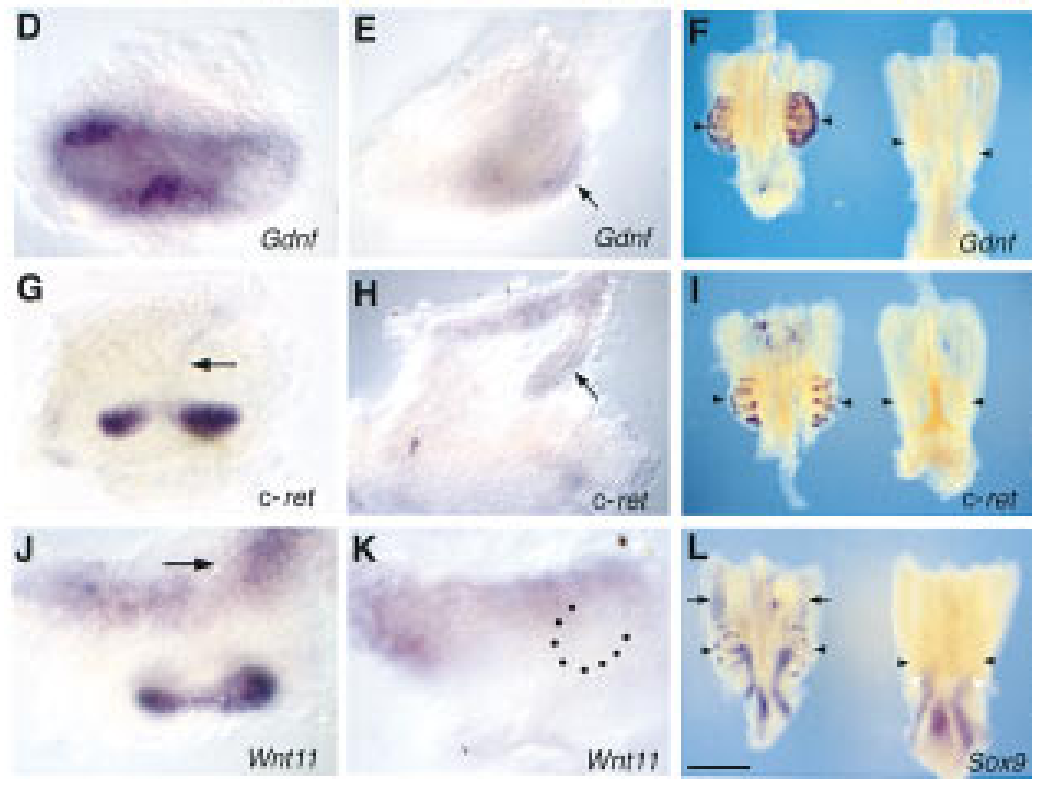

(F) In 12.5-d.p.c. Hs2st mutant kidney rudiments, Gdnf transcripts are no longer detected. (G) At 11.5 d.p.c., c-ret transcripts are detectable throughout the ureteric bud (black arrow) and are abundant in the ureteric bud tips. $(\mathrm{H})$ In mutants at 11.5 d.p.c., c-ret expression in the ureteric bud is comparable to wild-type or heterozygous kidneys, but strong expression is not detected in the unbranched ureteric bud tip (black arrow). (I) At 12.5 d.p.c., c-ret transcripts are abundant in the bifurcated ureteric bud tips of the heterozygous or wild-type kidney and are no longer detectable in mutant kidney rudiments. (J) At 11.5 d.p.c., Wnt11 is expressed in ureteric bud tips and in mesenchyme proximal to the Wolffian duct (arrow). (K) In mutants, Wnt11 expression is undetectable in the unbranched ureteric bud (position highlighted by black dots). (L) In heterozygous or wild-type kidneys at 12.5 d.p.c., Sox 9 transcripts are detected in the ureteric system. In mutants, expression persists at apparently normal levels in the unbranched ureter (white arrowheads). Black arrows show expression of Sox9 in the male gonads [the mutant urogenital region is female and, therefore, does not express Sox9 in the gonad (Kent et al. 1996; Morais da Silva et al. 1996)]. Scale bar in L: $100 \mu m(A, B, D, E, G, H, J, K) ; 800 \mu m$ $(\mathrm{C}, \mathrm{F}, \mathrm{I}, \mathrm{L})$.

tected in RNA derived from homozygous embryos. The gene trap allele is predicted to encode a fusion protein with the highly conserved endogenous carboxyterminal 160 amino acids (out of a total of 356) replaced with a $\beta$-galactosidase-neomycin phosphotransferase fusion. This is likely to constitute a null al lele, but final proof requires a detailed biochemical analysis of sulfation status of heparan sulfate chains in mutant tissues.

Several documented human disorders involve abnormalities of the kidney, eye, skeleton, and palate (Online Mendelian Inheritance in Man, http://www3.ncbi. $\mathrm{nlm}$.nih.gov/omim). No human genetic disorders with defects reminiscent of the murine phenotype, however, have yet been associated with human chromosome 1p31, where we have shown that HS2ST maps. Likewise, there are no classical mouse mutations resembling the
Hs2st ${ }^{-1-}$ phenotype, which map to mouse chromosome $3 \mathrm{H}$.

\section{HSPGs can influence signaling interactions}

The HS2ST enzymatic activity characterized in $\mathrm{CHO}$ cells catalyzes 2-O-sulfation of L-iduronic acid in heparan sulfate but is thought not to transfer sulfate to other glycosaminoglycan substrates, such as dermatan sulfate, keratan sulfate, and chondroitin sulfate (Kobayashi et al. 1996, 1997). Therefore it is predicted that the Hs2st ${ }^{-1-}$ mutant phenotype stems I argely or exclusively from defects in heparan sulfate molecules. Deficiency in 2-Osulfation may be accompanied by a secondary increase in $\mathrm{N}$-sulfated glucosamine residues in heparan sulfate and altered degradation products (Bai and Esko 1996; Bai et al. 1997), and some of these modifications may have additional biological significance. Several biochemical and 


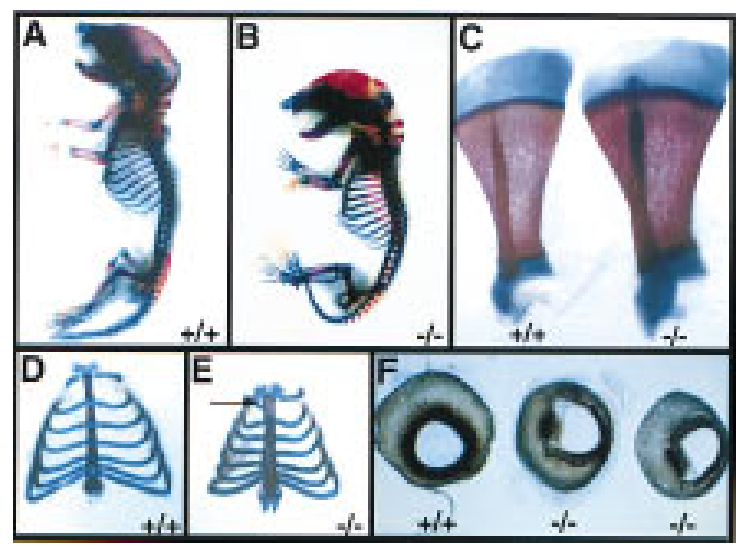

Figure 7. Defects of the skel eton and the eye in newborn Hs2st mutants. (A-D) Alcian blue-al izarin red skel etal preparations of wild-type (A, D, and left-hand specimen in C) and Hs2st mutant $(B, D$, and right-hand specimen in $C$ ) newborn mice (ossified tissue, red; cartilage, blue). Compared with wild types (A), $\mathrm{Hs} 2 \mathrm{st}^{-1-}$ mice (B) exhibit skel etal abnormalities associated with increased bone mineralization. N ote proximal shortening and increased girth of the long bones in mutants. (C) Wild-type and mutant scapulae. Note increased girth in the mutant. (D,E) Comparison of mutant and wild-type rib cages. In the wild type (D), costal cartilage crosses the sternum. In mutants $(E)$, the sternum is fused. Additional patterning abnormalities are often observed (arrow). N ote the decreased width of the mutant rib cage. (F) Comparison of mutant and wild-type eyes. Hs2st mutants exhibit iris colobomas associated with defective pigmented epithelium differentiation.

in vitro studies have shown that 2-O-sulfation in particular is essential if heparan sulfate is to interact with certain growth factors such as FGF-2 (basic FGF; Turnbull et al. 1992; Maccarana et al. 1993; Bai and Esko 1996). This modification appears not to be required for the interaction of hepatocyte growth factor with its receptor (Lyon et al. 1994). Therefore, modulating the levels of 2-O-sulfation may confer an additional level of specificity on some, but not all, growth factor-receptor interactions. HSPG structure varies extensively between tissues during development (Bernfield et al. 1992), and one means of achieving this diversity is illustrated here by the regulated expression of Hs2st. Several embryonic signaling centres, such as the node and floor plate, show el evated expression of the gene, and there is a clear example of its apparent down-regulation on epithelialization of the metanephric mesenchyme.

There is increasing evidence that HSPGs can modulate the activity of growth factors through a number of mechanisms, including facilitating their di merization or altering their effective concentration by acting as lowaffi nity receptors (Schlessinger et al. 1995). Recently, genetic studies in Drosophila have demonstrated a rol e for heparin-like glycosaminoglycans in the reception of the Wingless (Wg) signal (Binari et al. 1997; Häcker et al. 1997; Haerry et al. 1997). Embryos that are either deficient in an enzyme catalyzing the production of a glycosaminoglycan precursor or that have been treated with an enzyme that specifically degrades heparan gly- cosaminoglycans, exhibit phenotypes reminiscent of loss-of-Wingless signaling. It has also been suggested that changes in HSPG expression may influence the distance over which a morphogen such as Wg can act; restricting it to a short-range signal in some circumstances but allowing it to serve as a more widespread gradient morphogen in others (Häcker et al. 1997). Therefore, it is likely that modulating the sulfation status of HSPGs will influence the availability of critical ligands and it is tempting to speculate that the $\mathrm{Hs}_{2 \mathrm{st}}{ }^{-1-}$ phenotype is due, at least in part, to the suboptimal presentation of signal ing molecules to their receptors.

\section{Consequences of the Hs2st mutation}

Previous experiments on early kidney development in vitro showed that the somewhat indiscriminate inhibition of de novo glycosaminoglycan sulfation by chlorate reversibly blocks ureteric bud growth and branching but does not affect nephrogenesis (Davies et al. 1995). The phenotype observed in $\mathrm{Hs} 2 \mathrm{st}^{-1-}$ mutants, however, indicates an earlier requirement for 2-O-sulfation in the initial condensation of the metanephric mesenchyme. During collecting duct morphogenesis, Hs2st does not seem to be required for the initial outgrowth of the ureteric bud from the Wolffian duct but rather for its subsequent branching foll owing contact with the metanephric mesenchyme. This suggests that it is required downstream of genes such as Wt1, Pax2, c-ret, and Gdnf (Kreidberg et al. 1993; Schuchardt et al. 1994, 1996; Torres et al. 1995; M oore et al . 1996; Pichel et al. 1996; Sanchez et al. 1996), which are implicated in ureteric bud outgrowth, but upstream of other genes such as Wnt4 and Bmp7 that are necessary for normal nephrogenesis (Stark et al. 1994; Dudley et al. 1995; Luo et al. 1995).

Interestingly, the metanephric phenotype of mice homozygous for a mutation in the homeobox gene Emx2, which is expressed in the ureteric bud (M iyamoto et al. 1997), is strikingly similar to that of $\mathrm{Hs}^{2} \mathrm{st}^{-1-}$. In both mutants, kidney development is arrested at the same stage and both show a very consistent phenotype, unlike the variability seen in Gdnf and c-ret mutants, which ranges from complete absence of ureteric bud to the development of small kidneys (Schuchardt et al. 1994; Moore et al. 1996). This suggests that there may be additional signaling mechanisms involving molecules other than Ret and GDNF that are regulated by Emx2 in the ureteric bud and require the mediation of HSPGs.

FGF-2 can substitute for the ureteric bud to induce mesenchymal condensation and prevent apoptosis in cultured metanephric mesenchyme (Perantoni et al. 1995). Interestingly, FGF-2 stimulates growth and inhibits differentiation of chondrocytes (Suzuki 1992) and this effect is likely to depend on the presence of sulfated glycosaminoglycans as their removal by chlorate promotes chondrocyte differentiation (Chintala et al. 1995). Therefore, impai red FGF-2 signal ing could explain many of the defects observed in $\mathrm{Hs} 2 \mathrm{st}^{-1}$-mutants. Mice homozygous for a null mutation in Fgf2, however, show no overt defects in kidney morphogenesis or skeletogenesis ( $R$. 
Dono and R. Zeller, pers. comm.) demonstrating that simple failure of FGF-2 signaling is not an adequate explanation for the Hs2st mutant phenotype. Because other members of the FGF family are expressed in the developing kidney (Finch et al. 1995), the phenotype observed in $\mathrm{Hs}_{2} \mathrm{st}^{-1-}$ embryos may be attributable to perturbation of more than one FGF-signaling pathway.

Cells expressing a vertebrate wg homolog Wnt1 can induce tubulogenesis in isolated metanephric mesenchyme (Herzlinger et al. 1994). Wnt1, however, is not itself expressed in the embryonic kidney, indicating that other Wnt family members may normal ly be responsible for early inductive events in metanephric development. The expression of Wnt4 is consistent with such a role although it appears to be required later than Hs2st. The metanephric mesenchyme of Wnt $4^{-1-}$ mutants does condense but fails to transform into an epithelium (Stark et al. 1994). Wnt11 is expressed at the ureteric bud tips and therefore it may contribute to mesenchymal induction (Kispert et al. 1996). If so, its signaling, like that of Wg in Drosophila, may be compromized in the absence of appropriately sulfated HSPGs.

It is also possible that failure to undergo changes in adhesion could contribute to the $\mathrm{Hs}_{2} \mathrm{st}^{-1-}$ phenotype. HSPGs can interact with a variety of matrix components via their heparan-sulfate chains, including certain collagens, tenascin, thrombospondin, and fibronectin and can be concentrated in focal adhesions (for review, see Bernfield et al. 1992; Woods and Couchman 1994). Clearly metanephric mesenchymal condensation requires alterations in adhesive properties and defective sulfation might prevent such changes. The transmembrane HSPG Syndecan-1 can regulate cell adhesion and cell morphology (Leppä et al. 1992) and is up-regulated dramatically in the metanephric mesenchyme on induction (Vainio et al. 1989). Therefore, it is possible that its function is compromized by the Hs2st mutation. At present, the potential roles of Hs2st in modulating signaling and adhesive properties cannot be distinguished and it is possible that both are important in kidney development.

\section{Late onset and restricted pattern of phenotype}

It is intriguing, considering the gene's widespread early expression, that Hs2st is not essential for early embryogenesis and that certain tissues that express Hs2st later in development, such as the lungs and teeth (data not shown), appear to devel op normally in the mutants. Although it is possible that 2-O-sulfation is only required in the developing kidney, skeleton, and eye it is more likely that in other tissues and organs HS2ST function may becompensated for by other sulfotransferases. It has been suggested, based on biochemical experiments, that there may be more than one type of 2-O-sulfotransferase activity (Wlad et al. 1993). Moreover, a human EST distinct from the human homolog of Hs2st shows greater similarity to Hs2st than to any other sulfotransferase (Fig. 1B; unpubl.). Therefore the phenotype of $\mathrm{Hs}_{2 \mathrm{st}}{ }^{-1}$ embryos may reflect those sites where HS2ST is the only 2-O-sulfation enzyme expressed.

\section{Materials and methods}

Production of gene trap ES cells

Electroporation and selection of CGR8 (129/Ola) ES cells was performed as described (Skarnes et al. 1995). The vector pGT tm0 was a gift from W. Skarnes and forms fusion proteins in a different open reading frame (ORF) to the parent plasmid pGT 1.8TM (Skarnes et al. 1995). The vector contains a splice acceptor sequence upstream of CD4 transmembrane domain sequence, a lacZ-neomycin phosphotransferase fusion ( $\beta$-geo) and a polyadenylation signal such that integrations into introns of transcriptionally active genes will produce a $\beta$-galactosidase ( $\beta$-gal) fusion protein that contains endogenous sequence amino-terminal to the site of insertion. The inclusion of a transmembrane domain-encoding region in the vector enriches for insertions downstream of secretory signal sequences or type II transmembrane domains because $\beta$-gal activity is only preserved when the enzyme is retained in the cytoplasm (Skarnes et al. 1995).

The vector was electroporated into $1 \times 10^{8}$ CGR8 ES cells. Colonies (149) resistant to G418 were recovered and 39 (26\%) of these exhibited $\beta$-gal activity. In 16 of these clones, $\beta$-gal activity showed a subcellular localization typical of fusion with a secreted or transmembrane protein (Skarnes et al. 1995). Chimeras were generated from these cells and the ES cell line ST 125 was one integration selected for further analysis on the basis that lacZ reporter gene expression was evident in 8.5- and 9.5-d.p.c. chimeric embryos.

\section{Rapid amplification of CDNA ends}

Total RNA was isolated from the ST 125 cell line using the guanidinium thiocyanate method (Chomczynski and Sacchi 1987). cDNA was synthesized from $5 \mu \mathrm{g}$ of total RNA and 5 ' rapid amplification of CDNA ends (RACE) performed using the Marathon CDNA amplification kit (Clontech) according to manufacturer's instructions. Following adaptor ligation, 35 cycles of PCR were conducted using Marathon adaptor primer 1 (5'-CCATCCTAATACGACTCACTATAGGGC-3') and a primer specific to the $C D 4$ transmembrane domain region (5'-TGAAGGGTGAGTGGGAGCGTTT-3'). A 1/50 dilution of the PCR products was subjected to 30 cycles of nested PCR [adaptor primer 2 (5'-ACTCACTATAGGGCTCGAGCGGC3'), CD4 primer 2 (5'-AGTAGACTTCTGCACAGACACC-3')] and gene trap RACE products verified using Southern blotting and hybridization with an end-labeled oligonucleotide probe specific for the En-2 exon sequence in the gene trap vector ( $5^{\prime}$ GTCCCAGGTCCCGAAAACCAAAGAAGAAGAACG-3') using standard procedures. Following size-selection of hybridizing products (Quiaex II Gel Extraction Kit, Quiagen), Notl-Pstl-digested fragments were cloned into pSPORT1 (GIBCO-BRL). Plasmids harboring gene trap products were identified using a diagnostic BgllI-Smal digest followed by manual DN A sequencing (U.S. Biochemical Manual Sequencing Kit). The BLAST algorithm (Altshul et al. 1990) was used to search the databases for sequence homologies.

\section{Isolation of cDNA and genomic clones}

PCR employing primers specific to the ST $1255^{\prime}$ RACE product (5'-GCAGGATGCAACTCTGGATG-3' and 5'-GCCTCTCAATAGGGTCCCTGAT-3') was used to amplify a 319-bp probe, termed ST $125 \mathrm{~A}$, which was used to screen a 8.5-d.p.c. mouse embryo cDN A $\lambda$ GT 10 library (Farhner et al. 1987) using standard procedures. T wo independent clones representing fulllength Hs2st cDN As were isolated. The same probe was used to 
isolate bacteriophage $\lambda$ clones harboring genomic DNA inserts corresponding to the mouse Hs2st gene from a CGR8 ES cell $\lambda \mathrm{KO}$ genomic library ( $\mathrm{N}$ ehls et al. 1994) and the human HS2ST gene from a human fibrosarcoma cell line genomic $\lambda D A S H I I$ library [Stratagene; hybridization: $0.5 \mathrm{M}$ phosphate buffer (pH7.2), 7\% SDS, $1 \mathrm{~mm}$ EDTA at $50^{\circ} \mathrm{C}$ for $16 \mathrm{hr}$; Washes: $2 \times$ $\mathrm{SSC} / 0.1 \%$ SDS at $50^{\circ} \mathrm{C}, 3$ times]. Xenopus laevis Hs2st cDN As were isolated from an amplified gastrula cDN A library in U niZAP XR (Cho et al. 1991) using low-stringency screening. Filters were hybridized with the mouse ST $125 \mathrm{~A}$ probe in 30\% formamide, $5 \times$ SSC, $5 \times$ Denhardt's solution, $0.02 \% \mathrm{~N}$ aPP, $0.1 \%$ SDS, $0.1 \mathrm{mg} / \mathrm{ml}$ of yeast tRNA, $0.03 \mathrm{~m}$ phosphate buffer $(\mathrm{pH} \mathrm{6.5)}$ at $37^{\circ} \mathrm{C}$ and washed in $2 \times \mathrm{SSC} / 0.1 \%$ SDS 3 times at $37^{\circ} \mathrm{C}$.

FISH and karyotyping

Metaphase chromosome spreads were made from ST125 ES cells or human blood lymphocyte preparations using standard procedures (Robertson 1987). To determine the localization of Hs2st and the gene trap insertion, Giemsa banding was carried out (Klever et al. 1991) and 15 spreads from each of two slides were recorded as digital images using Quips Capture software (Vysis) along with their position on the slide. One slide was hybridized to a $12-\mathrm{kb}$ mouse genomic $\mathrm{Hs} 2 \mathrm{st}$ probe, and the other to a gene trap vector-specific probe. Chromosomes showing hybridization on the captured spreads were compared with the corresponding Giemsa-banded image. The chromosome was identified by karyotyping using Quips Karyotyper software $(\mathrm{Vy}$ sis). This analysis additionally confirmed the absence of cytogenetical ly visible chromosome anomal ies. A similar procedure was used to identify the chromosomal localization of human HS2ST, using a 16-kb human genomic probe. To show colocalization of the gene trap vector insertion with mouse Hs2st in ST 125 cells, double FISH was carried out (Fantes et al. 1995) using a digoxigenin-label ed $\mathrm{Hs} 2 \mathrm{st}$ probe and a bi otinylated gene trap vector probe.

\section{Radiation hybrid mapping}

An intron-specific portion of human HS2ST was subcloned and the sequence used to design primers that specifically amplified a 101-bp PCR fragment from human, but not hamster DNA (5'-TGTGAACCATGTTAGCCA-3', 5'-TGAAATCAAAAGATGCTG-3'). These were used to screen the GeneBridge 4 human-hamster radiation hybrid panel (Gyapay et al. 1996). Data were submitted to the Human Genome Mapping Project and mapped using the Whitehead Institute statistical program $\mathrm{RH}$ MAPPER.

\section{ES cell chimeras and transgenic mice}

Mice were maintained on a 10-hr light, 14-hr dark cycle. N oon on the day of finding a vaginal plug was designated 0.5 d.p.c. Germ-line mice were generated by injection of ST 125 ES cells into C57/BL6 blastocysts followed by transfer to a foster mother (Hogan et al. 1994). Chimeric male mice were mated to C57/BL6 females and $F_{1}$ progeny analyzed for the presence of the transgene. Heterozygous animals were backcrossed onto a C57/BL6 background and heterozygous siblings intercrossed.

\section{Recovery of embryos and lacZ expression pattern analysis}

Embryos were dissected from the uterus in M 2 medium containing $10 \%$ fetal bovine serum (Advanced Protein Products) as described (Hogan et al. 1994) and X-gal-stained overnight according to the method of Beddington et al. (1989). In all cases, transgenic samples were incubated with stage-matched wildtype tissues to control against endogenous $\beta$-gal activity. Ex vivo kidney cultures were performed as described before staining (Kispert et al. 1996).

\section{Genotyping procedures}

$\mathrm{Hs} 2 \mathrm{st}^{+1-}$ mice could be distinguished from wild-type littermates by X-gal staining of tail biopsies. To establish an allele-specific genotyping assay, Hs2st genomic sequences flanking the vector insertion site were amplified from lacZ-positive genomic DNA (High-fidelity PCR system; Boehringer M annheim), cloned and sequenced. Subsequently, PCR primers were designed such that a common primer, specific to sequences $5^{\prime}$ to the insertion $\left(5^{\prime}\right.$ ATCAATGAATAATTGCCTAGGTC-3') was used in conjunction with a primer specific to sequences $3^{\prime}$ to the insertion (5'-GGGAAGAAATTCACCCCAACA-3') and a primer that recognizes sequences in the gene trap vector ( $5^{\prime}$-TACTCAGTGCAGTGCAGTCA-3') to generate 344- and 174-bp products specific to the mutant and wild-type alleles, respectively. Genomic DNA (500 ng) was denatured at $94^{\circ} \mathrm{C}$ for $5 \mathrm{~min}$ and immediately transferred to ice before amplification in a $20-\mu \mathrm{l}$ reaction volume $[0.6 \mu \mathrm{m}$ each primer, $50 \mathrm{~mm} \mathrm{KCl}, 10 \mathrm{~mm}$ Tris- $\mathrm{HCl}(\mathrm{pH}$ 8.3), $1 \mathrm{~mm} \mathrm{M} \mathrm{gCl}, 100 \mu \mathrm{M}$ dNTPs, 1 unit of Amplitaq (Perkin-Elmer)], to $30 \mathrm{cycles}\left(94^{\circ} \mathrm{C}\right.$ for $20 \mathrm{sec}, 60^{\circ} \mathrm{C}$ for 30 $\mathrm{sec}, 72^{\circ} \mathrm{C}$ for $\left.30 \mathrm{sec}\right)$ and a single elongation step $\left(72^{\circ} \mathrm{C}\right.$ for 5 $\min )$.

\section{Northern hybridization}

Total RNA was isolated from individual 15.5-d.p.c. embryos recovered from an intercross of heterozygous Hs2 $\mathrm{st}^{+1-}$ parents using the method of Chomczynski and Sacchi (1987), following harvesting of yolk sacs for DN A genotyping. Total RN A (10 $\mu \mathrm{g})$ from embryos of each genotype was electrophoresed in a 1.5\% formal dehyde-agarose gel as described (Sambrook et al. 1989) and transferred to Hybond $\mathrm{N}$ membrane (A mersham) according to manufacturer's instructions. The membrane was hybridized at $65^{\circ} \mathrm{C}$ with the ST $125 \mathrm{~A}$ probe in $5 \times$ Denhardt's, $4 \times$ SSC, 50 $\mathrm{mM} \mathrm{NaH} \mathrm{PO}_{4}, 10 \%$ dextran sulfate and washed in $0.5 \times \mathrm{SSC} /$ $0.1 \% \mathrm{SDS}$ and then $0.2 \times \mathrm{SSC} / 0.1 \% \mathrm{SDS}$ at $65^{\circ} \mathrm{C}$ before autoradiography. The membrane was reprobed with a $\beta$-actin CDNA probe (Harrison et al. 1995).

Whole-mount in situ hybridization and immunohistochemistry

Whole-mount in situ hybridization was performed as described (Wilkinson 1992) with two modifications. Urogenital ridges were treated for $30 \mathrm{~min}$ in $20 \mu \mathrm{g} / \mathrm{ml}$ proteinase $\mathrm{K}$ (as opposed to $15 \mathrm{~min}$ in $10 \mu \mathrm{g} / \mathrm{ml}$ for embryos and dissected kidneys) and, in all cases, embryo powder was omitted from the procedure. Digoxigenin-labeled antisense riboprobes were generated as described previously for Gdnf and c-ret (Durbec et al. 1996), Wnt11 (Kispert et al. 1996), and Sox9 (Morais da Silva et al. 1996). The Hs2st antisense riboprobe was transcribed from a cDN A clone representing amino acids 8-330.

For whole-mount immunohistochemistry, urogenital ridges were fixed in 4\% PFA for 15 min, washed once in PBS containing $1 \%$ Triton $X-100$ and several times in PBS containing $0.1 \%$ Triton $\mathrm{X}-100$. Following an overnight incubation at $4^{\circ} \mathrm{C}$ in a 1:400 dilution of anti-Pax-2 IgG (D ressler and Dougl ass 1992) in PBS, Pax-2 expression was detected using a horseradish peroxidase (HRP)-conjugated goat anti-rabbit IgG secondary antibody (Sigma Immunochemicals) as described (Kispert and Herrman 1994). 
Skeletal preparations and histochemistry

Skel etal preparations of newborn mice were made using an alcian blue-alizarin red method as described (Kessel and Gruss 1991) and hematoxylin and eosin staining was performed according to Kaufman (1992).

\section{Acknowledgments}

R.S.P.B. is an International scholar of the Howard Hughes M edical Institute and V.W. is a MRC Career Development Fellow. We are grateful to V. Pachnis, R. Lovell-Badge, S. Vainio, J. Bard, and $\mathrm{W}$. Skarnes for the kind provision of reagents. We thank $M$ arie-Odile Ott for contributing to the initial gene trap screen, Ronald Wilkie for technical assistance, the Dunkin Green staff for excellent animal care, Rosanna Dono, Rolf Zeller, Cindi Merrill, and Barry Ganetzky for communicating unpublished results, and John Gallagher for useful discussion of the manuscript. The sequences of the mouse and Xenopus Hs2st cDN As have been submitted to GenBank under accession nos. AF060178 and AF060179.

The publication costs of this article were defrayed in part by payment of page charges. This article must therefore be hereby marked "advertisement" in accordance with 18 USC section 1734 solely to indicate this fact.

\section{References}

Altschul, S.L., W. Gish, W. Miller, E.W. Myers, and D.J. Lipman. 1990. Basic local alignment search tool. J. Mol. Biol. 215: 403-410.

Bai, X. and J.D. Esko. 1996. An animal cell mutant defective in heparan sulfate hexuronic acid 2-O-sulfation. J. Biol. Chem. 271: 17711-17717.

Bai, X., K.J. Bame, H. Habuchi, K. Kimata, and J.D. Esko. 1997. Turnover of heparan sulfate depends on 2-O-sulfation of uronic acids. J. Biol. Chem. 272: 23172-23179.

Bard, J.B.L., J.A. Davies, I. Karavanova, E. Lehtonen, H. Sariola, and S. Vainio. 1996. Kidney development: The inductive interactions. Sem. Cell. Dev. Biol. 7: 195-202.

Beddington, R.S.P., J. Morgenstern, H. Land, and A. Hogan. 1989. An in situ transgenic enzyme marker for the midgestation mouse embryo and the visualization of inner cell mass clones during early organogenesis. Development 106: 37-46.

Bernfield, M., R. Kokenyesi, M. Kato, M.T. Hinkes, J. Spring, R.L. Gallo, and E.J. Lose. 1992. Biology of the Syndecans: A family of transmembrane heparan sulfate proteoglycans. Annu. Rev. Cell. Biol. 8: 365-393.

Binari, R.C., B.E. Stavely, W.A. Johnson, R. Godavarti, R. Sasisekharan, and A.S. Manoukian. 1997. Genetic evidence that heparin-like glycosaminoglycans are involved in wingless signaling. Development 124: 2623-2632.

Chintala, S.K., R.R. Miller, and C.A. McDevitt. 1995. Role of heparan sulfate in the terminal differentiation of growth plate chondrocytes. Arch. Biochem. Biophys. 316: 227234.

Cho, K.W., B. Blumberg, H. Steinbesser, and E.M. DeRobertis. 1991. M olecular nature of Spemann's organizer: The role of the Xenopus homeobox gene goosecoid. Cell 67: 1111-1120.

Chomczynski, P. and N. Sacchi. 1987. Single step method of RNA isolation by guanidinium thiocyanate-phenol-chloroform extraction. Anal. Biochem. 162: 156-159.

Davies, J., M. Lyon, J. Gallagher, and D. Garrod. 1995. Sul phated proteoglycan is required for collecting duct growth and branching but not for nephron formation during kidney development. Development 121: 1507-1517.

DeBry, R.W. and M.F. Seldin. 1996. Human/mouse homology relationships. Genomics 33: 337-351.

Dressler, G.R. and E.C. Douglass. 1992. Pax-2 is a DN A-binding protein expressed in embryonic kidney and Wilms tumor. Proc. Natl. Acad. Sci. 89: 1179-1183.

Dressler, G.R., U. Deutsch, K. Chowdury, H.O. N ornes, and P. Gruss. 1990. Pax2, a new murine paired-box-containing gene and its expression in the developing excretory system. Development 109: 787-795.

Dudley, A.T., K.M. Lyons, and E.J. Robertson. 1995. A requirement for bone morphogenetic protein-7 during development of the mammalian kidney and eye. Genes \& Dev. 9: 27952807.

Durbec, P., C.V. Marcos-Gutierrez, C. Kilkenny, M. Grigoriou, K. Wartiowaara, P. Suvanto, D. Smith, B. Ponder, F. Constantini, M. Saarma, H. Sariola, and V. Pachnis. 1996. GDN F signaling through the Ret receptor tyrosine kinase. Nature 381: 789-793.

Fantes, J.A., K. Oghene, S. Boyle, S. Danes, J.M. Fletcher, E.A. Bruford, K. Williamson, A. Seawright, A. Schedl, I. Hanson, G. Zehetner, R. Bhogal, H. Lehrach, S. Gregory, J. Williams, P. Little, G. Sellar, J. Hoovers, M. Mannens, J. Weissenbach, C. Junien, V. van Heyningen, and W.A. Bickmore. 1995. A high-resolution integrated physical, cytogenetic, and genetic map of human chromosome 11: Distal p13 to proximal p15.1. Genomics 25: 447-461.

Farhner, K., B.L.M. Hogan, and R. Flavell. 1987. Transcription of $\mathrm{H}-2$ and Qa genes in embryonic and adult mice. EMBO J. 6: 1265-1271.

Finch, P.W., G.R. Cunha, J.S. Rubin, J. Wong, and D. Ron. 1995. Pattern of keratinocyte growth factor and keratinocyte growth factor receptor expression during mouse fetal development suggests a role in mediating morphogenetic mesenchymal-epithelial interactions. Dev. Dyn. 203: 223-240.

Gallagher, J.T., M. Lyon, and W.P. Steward. 1986. Structure and function of heparan sulphate proteoglycans. Biochem. J. 236: 313-325.

Grobstein, C. 1953. Inductive epithelio-mesenchymal interactions in cultured organ rudiments of the mouse. Science 118: 52-55.

Gyapay, G., K. Schmitt, C. Fizames, H. Jones, N. Vega-Czarny, D. Spillett, D. Muselet, J.F. Prud'Homme, C. Dib, C. Auffray, J. Morissette, J. Weissenbach, and P.N. Goodfellow.1996. A radiation hybrid map of the human genome. Hum. Mol. Genet. 5: 339-346.

Häcker, U., X. Lin, and N. Perrimon. 1997. The Drosophila sugarless gene modulates Wingless signaling and encodes an enzyme involved in polysaccharide biosynthesis. Development 124: 3565-3523.

Haerry, T.E., T.R. Heslip, J.L. M arsh, and M.B. O'Connor. 1997. Defects in glucuronate biosynthesis disrupt Wingless signaling in Drosophila. Development 124: 3055-3064.

Harrison, S.M., S.L. Dunwoodie, R.M. Arkell, H. Lehrach, and R.S.P. Beddington. 1995. Isolation of novel tissue-specific genes from cDN A libraries representing the individual tissue constituents of the gastrulating mouse embryo. Development 121: 2479-2489.

Hashimoto, Y., A. Orrelana, G. Gil, and C.B. Hirschberg. 1992. M olecular cloning and expression of rat liver $\mathrm{N}$-heparan sulfate sulfotransferase. J. Biol. Chem. 267: 15744-15750.

Herzlinger, D., J. Qiao, D. Cohen, N. Ramakrishna, and A.M.C. Brown. 1994. Induction of epithelial morphogenesis by cells expressing Wnt-1. Dev. Biol. 166: 815-818.

Hogan, B., R. Beddington, F. Constantini, and E. Lacy. 1994. 
Manipulating the mouse embryo: A laboratory manual. Cold Spring Harbor Laboratory Press, Cold Spring Harbor, NY.

Kaufman, M.H. 1992. The atlas of mouse development. Academic Press, London, UK.

Kato, M., H. Wang, M. Bernfield, J.T. Gallagher, and J.E. Turnbull. 1994. Cell surface Syndecan-1 on distinct cell types differs in fine structure and ligand binding of its heparan sulphate chains. J. Biol. Chem. 269: 18881-18890.

Kent, J., S.C. Wheatley, J.E. Andrew, A.H. Sinclair, and P. Koopman. 1996. A male-specific role for SOX9 in vertebrate sex determination. Development 122: 2813-2822.

Kessel, M. and P. Gruss. 1991. Homeotic transformations of murine vertebrae and concomitant alteration of Hox codes induced by retinoic acid. Cell 67: 89-104.

Kispert, A. and B.G. Herrmann. 1994. Immunohistochemical analysis of the Brachyury protein in wild-type and mutant mouse embryos. Dev. Biol. 161: 179-193.

Kispert, A., S. Vainio, L. Shen, D.H. Rowitch, and A.P. McMahon. 1996. Proteoglycans are required for maintenance of Wnt-11 expression in the ureter tips. Development 122: 3627-3637.

Klagsbrun, M. and A. Baird. 1991. A dual receptor system is required for basic fibroblast growth factor activity. Cell 67: 229-231.

Klever, M., C. Grond-Ginsbach, H. Scherthan, and T.M. Schroeder-Kurth. 1991. Chromosomal in situ suppression hybridization after Giemsa banding. Hum. Genet. 86: 484486.

Kobayashi, M., H. Habuchi, O. Habuchi, M. Saito, and K. Kimata. 1996. Purification and characterization of heparan sulfate 2-sulfotransferase from cultured chinese hamster ovary cells. J. Biol. Chem. 271: 7645-7653.

Kobayashi, M., H. Habuchi, M. Yoneda, O. Habuchi, and K. Kimata. 1997. Molecular cloning and expression of chinese hamster ovary cell Heparan sulfate 2-sul fotransferase. J. Biol. Chem. 272: 13980-13985.

Kreidberg, J.A., H. Sariola, J.M. Loring, M. M aeda, J. Pelletier, D. Housman, and R. Jaenisch. 1993. WT-1 is required for early kidney development. Cell 74: 679-691.

Lee, J.J., S.C. Ekker, D.P. von Kessler, J.A. Porter, B.I. Sun, and P.A. Beachy. 1994. Autoproteolysis in hedgehog protein biogenesis. Science 266: 1528-1537.

Leppä, S., M. Mali, H.M. Miettenen, and M. Jalkanen. 1992. Syndecan expression regulates cell morphology and growth of mouse mammary epithelial tumor cells. Proc. Natl. Acad. Sci. 89: 931-936.

Luo, G., C. Hofmann, A.L.J.J. Bronckers, M. Sohocki, A. Bradley, and G. Karsenty. 1995. BM P-7 is an inducer of nephrogenesis, and is also required for eye development and skeletal patterning. Genes \& Dev. 9: 2808-2820.

Lyon, M., J.A. Deakin, K. Mizuno, T. N akamura, and J.T. GalIagher. 1994. Interaction of hepatocyte growth factor with heparan sulfate. J. Biol. Chem. 269: 11216-11223.

Maccarana, M., B. Casu, and U. Lindahl. 1993. Minimal sequence in heparin/heparan sulfate required for binding of basic fibroblast growth factor. J. Biol. Chem. 268: 2389823905.

Miyamoto, N., M. Yoshida, S. Kuratani, I. Matsuo, and S. Aizawa. 1997. Defects of urogenital development in mice lacking Emx2. Development 124: 1653-1664.

Moore, M.W., R.D. Klein, I. Farinas, H. Sauer, M. Armanini, H. Phillips, L.F. Reichardt, A.M. Ryans, K. Carver-M oore, and A. Rosenthal. 1996. Renal and neuronal abnormalities in mice lacking GDN F. Nature 382: 76-79.

Morais da Silva, S., A. Hacker, V. Harley, P. Goodfellow, A.
Swain, and R. Lovell-Badge. 1996. Sox9 expression during gonadal devel opment implies a conserved role for the gene in testis differentiation in mammals and birds. Nature Genet. 14: $62-68$.

N ehls, M., M. M esserle, A.J.H. Smith, and T. Boehm. 1994. Two large insert vectors, $\lambda$ PS and $\lambda K O$, facilitate rapid mapping and targeted disruption of mammalian genes. BioTechniques 17: 770-775.

N urcombe, V., M.D. Ford, J.A. Wildschut, and P.F. Bartlett. 1993. Developmental regulation of neural response to FGF-1 and FGF-2 by heparan sulphate proteoglycan. Science 260: 103-106.

Perantoni, A.O., L.F. Dove, and I. Karavanova. 1995. Basic fibroblast growth factor can mediate the early inductive events in renal development. Proc. Natl. Acad. Sci. 92: 4696-4700.

Pichel, J.G., L. Shen, H.Z. Sheng, A. Granholm, J. Drago, A. Grinberg, E.J. Lee, S. Ping Huang, M. Saarma, B.J. Hoffer, H. Sariola, and H. Westphal. 1996. Defects in enteric innervation and kidney devel opment in mice lacking GDN F. Nature 382: 73-76.

Powers, P.A. and B. Ganetzky. 1991. On the components of segregation distorter in Drosophila melanogaster. V. Molecular analysis of the Sd locus. Genetics 129: 133-144.

Rapraeger, A.C., A. Krufka, and B.B. Olwin. 1991. Requirement of heparan sulfate for bFGF-mediated fibroblast growth and myoblast differentiation. Science 252: 1705-1708.

Reichsman, F., L. Smith, and S. Cumberledge. 1996. Glycosaminoglycans can modulate extracellular localization of the wingless protein and promote signal transduction. J. Cell. Biol. 135: 819-827.

Robertson, E.J. 1987. Teratocarcinomas and embryonic stem cells: A practical approach. IRL Press, Oxford, UK.

Ruppert, R., E. Hoffmann, and W. Sebald. 1996. Human bone morphogenetic protein 2 contains a heparin-binding site which modifies its biological activity. Eur. J. Biochem. 237: 295-302.

Saksela, O. and D.B. Rifkin. 1990. Release of basic fibroblast growth factor complexes from endothelial cells by plasminogen activator-mediated proteolytic activity. J. Cell. Biol. 110: 767-775.

Sambrook, J., E.F. Fritsch, and T. Maniatis. 1989. Molecular cloning: A laboratory manual, 2nd ed. Cold Spring Harbor Laboratory Press, Cold Spring Harbor, NY.

Sánchez, M.P., I. Silos-Santiago, J. Frisen, B. He, S.A. Lira, and M. Barbacid. 1996. Renal agenesis and the absence of enteric neurons in mice lacking GDN F. Nature 382: 70-73.

Saxén, L. and M. Karkinen-Jääskeläinen. 1975. Inductive interactions in vertebrate morphogenesis. In The early development of mammals (ed. M. Balls and A. Wild), pp. 319-334. Cambridge University Press, Cambridge, UK.

Schlessinger, J., I. Lax, and M. Lemmon. 1995. Regulation of growth factor activation by proteoglycans: What is the role of the low affinity receptors? Cell 83: 357-360.

Schuchardt, A., V. D'A gati, L. Larsson-Bloomberg, F. Constantini, and V. Pachnis. 1994. Defects in the kidney and enteric nervous system of mice lacking the tyrosine kinase receptor Ret. Nature 367: 380-383.

Schuchardt, A., V. D'A gati, V. Pachnis, and F. Constantini. 1996. Renal agenesis and hypoplasia in ret-k- mutant mice results from defects in ureteric bud development. Development 122: 1919-1929.

Skarnes, W.C., J.E. M oss, S.M. Hurtley, and R.S.P. Beddington. 1995. Capturing genes encoding membrane and secreted proteins important for mouse development. Proc. Nat. Acad. Sci. 92: 6592-6596. 
Bullock et al.

Stark, K., S. Vainio, G. Vassileva, and A.P. McMahon. 1994. Epithelial transformation of metanephric mesenchyme in the devel oping kidney regulated by Wnt-4. Nature 372: 679683.

Suzuki, F. 1992. Effects of various growth factors on a chondrocyte differentiation model. Adv. Exp. Med. Biol. 324: 101106.

Torres, M., E. Gomez-Pardo, G.R. Dressler, and P. Gruss. 1995. Pax-2 controls multiplesteps of urogenital development. Development 121: 4057-4065.

Trupp, M., A. Arenas, M. Fainzilber, A. Nilsson, B. Sieber, M. Grigoriou, C. Kilkenny, E. Salazar-Grueso, V. Pachnis, U. Arumäe, H. Sariola, M. Saarma, C.F. Ibáñez. 1996. Functional receptor for GDNF encoded by the c-ret proto-oncogene. Nature 381: 785-789.

Turnbull, J.E., D.G. Fernig, Y. Ke, M.C. Wilkinson, and J.T. Gallagher. 1992. Identification of the basic Fibroblast Growth Factor binding sequence in fibroblast heparan sulfate. J. Biol. Chem. 267: 10337-10341.

Vainio, S., E. Lehtonen, M. Jalkanen, M. Bernfield, and L. Saxén. 1989. Epithelial-mesenchymal interactions regulate the stage specific expression of a cell surface proteoglycan, syndecan, in the developing kidney. Dev. Biol. 134: 283-391.

Vainio, S. and U. Müller. 1997. Inductive tissue interactions, cell signaling, and the control of kidney organogenesis. Cell 90: 975-978.

Vortkamp, A., K. Lee, B. Lanske, G.V. Segre, H.M. Kronenberg, and C.J. Tabin. 1996. Regulation of rate of cartilage differentiation by Indian Hedgehog and PTH-rel ated protein. Science 273: 613-622.

Wilkinson, D.G. 1992. Whole mount in situ hybridization of vertebrate embryos. In In situ hybridization. (ed. D. Wilkinson), pp. 75-83. IRL Press, Oxford, UK.

Wlad, H., M. M accarana, I. Eriksson, L. Kjellén, and U. Lindahl. 1993. Biosynthesis of heparin: Different molecular forms of 2-O-sulfotransferases. J. Biol. Chem. 269: 24538-24541.

Woods, A. and J.R. Couchman. 1994. Syndecan 4 heparan sulfate proteoglycan is a selectively enriched and widespread focal adhesion component. Mol. Biol. Cell. 5: 183-192.

Yayon, A., M. Klagsburn, J.D. Esko, P. Leder, and D.M. Ornitz. 1991. Cell surface, heparin-like molecules are required for binding of basic Fibroblast Growth Factor to its high-affinity receptor. Cell 64: 841-848. 


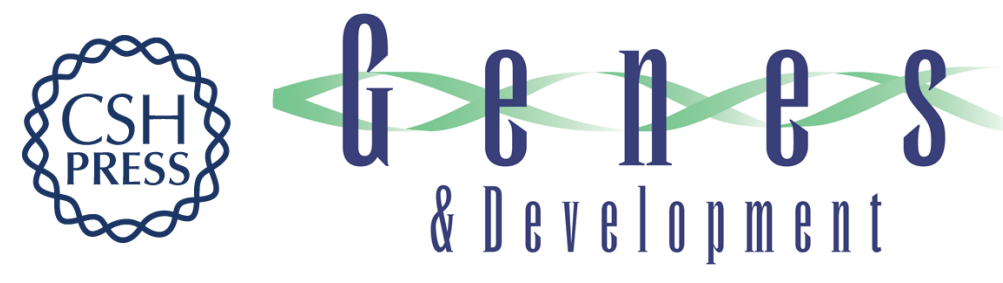

\section{Renal agenesis in mice homozygous for a gene trap mutation in the gene encoding heparan sulfate 2-sulfotransferase}

Simon L. Bullock, Judy M. Fletcher, Rosa S.P. Beddington, et al.

Genes Dev. 1998, 12:

Access the most recent version at doi:10.1101/gad.12.12.1894

References This article cites 69 articles, 37 of which can be accessed free at: http://genesdev.cshlp.org/content/12/12/1894.full.html\#ref-list-1

License

Email Alerting Receive free email alerts when new articles cite this article - sign up in the box at the top Service right corner of the article or click here.

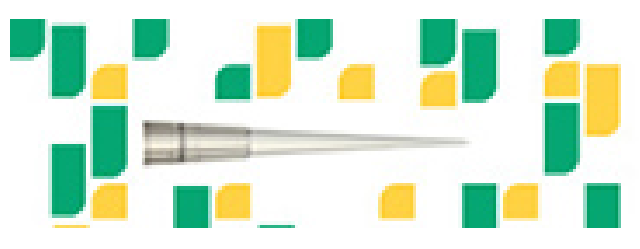

Focused on your science. 